\title{
PECHA KUCHA : A WAY TO DEVELOP PRESENTATION SKILL
}

\author{
Lulut Widyaningrum \\ UIN Walisongo Semarang \\ widyaningrum.lulut@yahoo.co.id
}

\begin{abstract}
This study is aimed at applying the adaptive Pecha Kucha technique to find out its effectiveness on students' explaining skill, one of the skills that should be mastered among ELT Department students. This study uses a Quasi-experimental with Randomized Control Group Pretest-Posttest. The two groups (experimental and control group) selected will be observed in which the experimental group is going to be taught how to use adaptive Pecha Kucha, while the control group will be asked to explore the traditional model of PPT presentation. The data are gained through observation, questionnaire, and comprehension test. The results show that the adaptive Pecha Kucha technique can develop students' explaining skill, performance and comprehension. With a good preparation and clear performance rule, the technique shows to be more effective than the common Power Point presentation. The data analysis of students comprehension shows that the t-statistics was 6.44 , while the value of $\mathrm{t}$-table with the significance level of 5\% and the Df (Degree of Freedom) 18 was 1. 734. It could be said that the t-statistics is higher than t-table. It also proved that the hypothesis which say there is significant different of exploring adaptive Pecha Kucha technique than students' Power Point presentation is accepted. It showed that adaptive Pecha Kucha is really effective to do the presentation. Though, the students need more time and preparation, this technique is badly employed due to its effectiveness and to support the pre-service teachers' development.
\end{abstract}

Keywords: Pecha Kucha, Presentation, Explaining Skill, Comprehension 


\section{Introduction}

Speaking skill is considered as one skill that needs special techniques and strategies due to some complexities happening during learning process. It is because speaking skill development is not simply a matter of learning language aspects yet it is an ongoing and complex of knowledge acquirement as well as skills and strategies development (Burns and Joyce, 1997: 55). However, judgment is often made to describe the teaching and learning output as people often simply make judgment about language competence based on someone's ability to speak. Speaking may be used to communicate something to achieve particular goals involving explaining, expressing ideas and opinions, negotiating and or solving problems, even maintaining and establishing social relationship (McDonough and Shaw, 2003: 134). With the extensive purposes of speaking, mastering the skill is highly needed to anyone who intends to perform communication including a teacher.

In a class, a teacher needs to carry interaction or communication with his or her students as the process will determine the success of teaching and learning process. The speaking skill is crucial for different purposes such as explaining, negotiating, even clarifying. The communication will run effectively when it is supported with good skill of speaking skill. This can be seen when the addressee can understand what the teacher talk to him or her.

In UIN Walisongo, the students of English Language Teaching (ELT) department require mastering speaking skill not only for communication purposes but also for instructional purposes. One of the reason is because the institution is committed to be a teacher education that prepares prospective teachers. One of the speaking purposes in classroom setting is to explain the materials to students. The skill is necessary because it becomes the core of knowledge transfer from teacher to students in teaching-learning stages. Students must have adequate practices to establish the skill either in class or in daily interaction. In class, students can maximize their practice through some subjects such as speaking, method of language teaching etc. Consequently, explaining skill needs adequate practices to be done, especially in speaking class and a technique is 
needed to establish the intended skill. Nation and Newton (2009: 14) justify that language learning goals are achieved with the use of particular techniques. There are various techniques to establish explaining skill one of them is Pecha Kucha technique.

Pecha Kucha is actually a technique used for presentation that draws its name from the Japanese term created by Astrid Klein and Mark Dytham. Through a distinct method, it makes a challenging, interesting and concising presentation. Its benefits and uses have been studied by researchers such as Beyer et al (2012) who compared student reaction to and memory of peer presentations using either a fast-paced, images only format (Pecha Kucha) or a traditional PowerPoint presentation and found that it may become a useful student presentation style that maintains similar levels of retention; and Lehtonen (2011) who argues that the Pecha Kucha presentation technique can be aligned with the model of SECI (socialization, externalization, combination, internalization) by Nonoka to look at competences from a perspective of knowledge creation. Therefore, it gains rave notices all over the world and has been used and adopted for different purposes such as business and creative work. The technique may avoid audiences feeling bored with the speaker (for this case is the teacher) facing and speaking to the screen and reading every word while explaining the lesson. The technique is not just a reading style but it is the style that allows anyone to speak beyond what is displayed on the slides. Of course, it needs proper preparation that can be conducted along with lesson plan and other teaching instruments. This technique offers students an option to practice public speaking especially explaining skills. With its advantages and challenges, this study attempts to apply the Pecha Kucha technique to find out its effectiveness on students' explaining skill, the skill that should be mastered by anyone especially teachers, among ELT Department students.

\section{Background Literature}

\section{Speaking}

As one of the four language skills, speaking has become a major focus of language teaching. Richard (2008:19) argues 
that speaking skill mastery in English has been a priority for many second language and foreign language learners. The learners often evaluate their language learning success based on how well their spoken language proficiency improve. Consequently, various techniques and teaching activities are developed as a response to obtain the goal. However, all those attempts should recognize the different functions of speaking needed by the learners.

The functions of speaking may be reflected in different types of oral production. Brown (2001) mentions kinds of oral production that reflect the speaking performance such as imitative, intensive, responsive, transactional, interpersonal, and intensive. Richard (2008) classifies the functions of speaking into three namely talk as interaction, talk as transaction, and talk as performance. Interpersonal dialog serves as interaction to establish and maintain social relationship while transactional language focuses on conveying and exchanging specific information. The extensive monolog refers to public talk in the form of producing oral repots, summaries, public announcements, even speeches. This function is will be explored further in this research. Each of those functions are quite distinct and need different techniques and strategies.

\section{Speaking Skill for College Students}

Adult learners will typically have different needs, purposes, and learning styles. In order develop speaking proficiency, it is necessary to examine factors affecting adults learner oral communication and skill and strategies used in communication. Shumin (2002) mentions some factors that influence adults learner oral communication such as age or maturational constraints, aural medium that plays significant role in both speaking and listening process, sociocultural factors that affect a lot the language learned, and affective factors that influence language learners success and failure. In addition, he proposes interactions as the key the speaking functions of interactional and transactional. Consequently, the teaching learning process that provides learn- 
er-learner interactions in the form of give-and-take exchange of messages that enable to convey messages and perfom in real life communication. For the activities that promote students' performance, Richards (2008) states that this type of talk usually tends to be in the form of monolog than dialog. Some of the class activities that could be done are giving a class report, giving a lecture, making sales presentation, giving a speech of welcome, even conducting a class debate. Those activities are made considering that this kind of activities are usually focus on both message and audience, predictable organization and sequencing, importance both form and accuracy, and written language look like, and monologic form. Among the very common activities used to foster the speaking performance is a presentation.

Presentation is considered as one of effective ways to develop speaking. The use of power point may enable the speaker to have a guided and organized speaking. Maryam (2011) suggests that Power Point can be used to teach speaking by inserting ClipArt or animation that makes the presentation more attractive. Recently, there are various techniques that can be used in presentation, especially that employ power point, one of them is Pecha Kucha technique. It is a technique using power point as the main medium which is used for different purposes such as business and creative work. Teacher also may use it in teaching since the technique can also be used to explain the material in different way. The explaining skill focused in this research is part of the performance function that covers main performance features mentioned above.

\section{Pecha Kucha}

Pecha Kucha is a presentation style used for different purposes. The format was devised by Astrid Klein and Mark Dytham from Poland in 2003. In Pecha Kucha presentation, it should be created 20-second automated, pictorial slides within a program such as PowerPoint where each automated slide contains no word but only pictures, photos, or graphics so the speaker has to speak 6 minutes and 40 seconds (www.pecha-kucha.org). 
The timing and style of Pecha Kucha are aimed at improving students presentation where the automization and and fast pace of the slide force the one who is going to give presentation to be organized so that each slide message can be captured.

\section{Methods}

\section{Design}

This study employs a Quasi-experimental with Randomized Control Group Pretest-Posttest will be explored. Two groups (experimental and control group) selected will be observed in which the experimental group is going to be taught how to use adaptive Pecha Kucha, while the control group will be asked to explore the traditional model of Power Point presentation. Both groups will be tested after the experiment.

\section{Population, Sample, and Sampling}

The 4th-semester students of English departement in 2014-2015 academic year consisted of three (3) classes were chosen as the population. The total number of population was 107 students. Because the number of population is more than 100 , sampling research can be conducted. Hence, in this study a simple random sampling is applied to get the number of respondents. It is based on the consideration that the population is regarded homogeneous. This fact is gotten based on their similar mean scores on previous semester's speaking scores. Moreover, this also emphasized by their lecturer who states that the students speaking ability on those three classes are almost the same.

\section{Method of Data Analysis}

The data of this study are gained through observation, questionnaire, and comprehension test. The data gained from the observation then described and analyzed qualitatively to picture what is happening during the presentation. Questionnaire is distributed to both the Experimental and Control Groups and analyzed. It is followed then with comprehension test to 
find out students comprehension based on their answer. Then, a comparison analysis of technique effectivenes to the Control Group and Experimental Group is made using T-Test formula.

\section{Findings}

\section{Observation}

The first group presentation, the adaptive Pecha Kucha groups presentation, has regulation based on Pecha Kucha guidelines such as the presentation is set with the time limit, the slide must be set to automatically change after 20 seconds so the speaker needs to explain adequately and briefly to match the time limit but keep the audience comprehension. Because this is adaptive, the thing modified is that the presenters are allowed to bring note during presentation. Bringing a note is not character of Pecha Kucha. In addition, the presentation slide should be about pictures with no words at all and the pictures must be connecting with the slide before and after. The pictures are aimed to attract the audience to carefully pay attention to the presentation.

There are some gudelines for the adaptive Pecha Kucha technique. The overall duration of presentation for every speaker is 6 minutes and 67 seconds. In addition, all of the presenters must obey the same regulation for both groups namely presenting the topics that are not familiar with the students. This rule is aimed to make sure that the adaptive Pecha Kucha technique helps the presenter's explanation skill to develop students comprehension.

During the performance, all of the presenters give adaptive Pecha Kucha based on the guidelines stated. The topics are not familiar to the audiences and the slides shown are containing pictures representing each story section that needs to be explained by the presenters. Each presenter chooses pictures that represent the story in which each picture connects each other and makes the flow of the story is coherent and cohesive. All of the presenters also use presentation notes as they are allowed to do so during presentation. 
The second group using Power Point presentation, also has some guidelines. The guidelines state that the presentation has longer time limit where the speakers are free to present the material. In this group, the speakers create the presentation slide based on their need such as putting words or pictures. The words are not limited to specific numbers and even the speakers do not put any picture at all to their slides. The topics presented are also similar to the previous group in which it must not be familiar to students to make sure that the technique is successful or not.

\section{Questionnaire}

The questionnaire is distributed to both groups, the adaptive Pecha Kucha group and Power Point presentation. The results of the questionnaire show the differences between the two groups during preparation stage. There are $90 \%$ of the respondents from adaptive Pecha Kucha group presentation who admit that Pecha Kucha technique needs more time for preparation while only $10 \%$ of the respondents who state that it does not need more time to prepare. It is quite different from the Power Point presenters who only $60 \%$ of them admitting that the presentation needs more time, while $40 \%$ of the respondents consider that it does not need more time to prepare.

The presenters of the adaptive Pecha Kucha need more time to prepare the presentation. All of them are in agreement that preparing it needs more than two hours. On the other hand, the presenters using Power Point need different time to prepare the presentation. $40 \%$ of presenters need more than two hours to prepare. There are $40 \%$ presenters who need one to two hours preparation and $20 \%$ presenters who need less than one hour to prepare. Those results lead to opinion that preparing Pecha Kucha is difficult thing to do. This result is as stated by $80 \%$ of the respondents since $20 \%$ of them believe that even preparing it takes more time but it is not considered difficult. Different results are shown by respondents of Power Point. There are $70 \%$ of them who admit preparing it is not difficult while only $30 \%$ of them who consider that it is not difficult. 
The application of the techniques either adaptive Pecha Kucha or Power Point Presentation is also viewed differently. The presenters of the Experimental Group, presenting the adaptive Pecha Kucha, consider that Pecha Kucha is somehow difficult or easy where $50 \%$ of them view it as difficult and $50 \%$ of the rest view it not difficult. Meanwhile, $90 \%$ of the Power Point presenters consider that applying Power Point for the materials is easy to do compared to $10 \%$ of presenters who consider that the presentation is difficult for materials. The condition implies to the time limit setting. The time limit difficulty is also influenced by the regulation set by each technique. The $60 \%$ of adaptive Pecha Kucha presenters believe that setting the Pecha Kucha time limit that match with the regulation is difficult, while $40 \%$ of them admit that it is not difficult. However, there are only $40 \%$ of the Power Point presenters who consider that setting the time limit is difficult. $60 \%$ of them believe that setting the presentation time limit is not difficult.

The last question related to preparation is matching all of the three aspects including material and the time limit. The presenters of adaptive Pecha Kucha consider that it is something difficult to do. It is stated by $80 \%$ of respondents compared to $20 \%$ of respondents who state that it is not difficult to do. On the other hand, the are only $30 \%$ of Power Point presenters who consider that matching all aspects is difficult while $70 \%$ of them believe that it is not difficult. These results describe how different the two groups are. After asking about preparation, the questions are then distributed to ask presenters' performance. Most of Pecha Kucha presenters perceived applying the technique is something challenging as stated by $90 \%$ respondents. It is different from just using Power Point to give presentation in which only $20 \%$ of respondents who state that using it is challenging or $80 \%$ of them believe that it is not challenging. It is interesting to note to the last question that all of presenters, $100 \%$, are in agreement that applying adaptive Pecha Kucha technique is challenging the students. There are only $20 \%$ of the Power Point presenters who admit that the technique is challenging the 
students. Most of them, $80 \%$, do not believe that the technique can challenge the students.

With the dificult preparation, Pecha Kucha technique helps the presenters to develop their creativity. This argument is stated by $90 \%$ percent of the respondents while the rest $10 \%$ states that it can not help the presenters creativity development. There are $60 \%$ of the Power Point presenters who consider that the technique can develop creativity and the rest $40 \%$ do admit it cannot develop the creativity. The last question is investigating whether the adaptive Pecha Kucha technique or Power Point can help the presenters develop their explaining skill. There are $80 \%$ Pecha Kucha presenters who believe that the technique can help them to explain better, while $20 \%$ of them admit that the technique cannot help them. The Power Point presenters also believe that Power Point can help them to explain better but the percentage is lower as stated by $70 \%$ of the respondents, while the rest 30\% consider that it cannot help them to explain better.

\section{Students' Comprehension}

The results of the Students' comprehension scores for Experimental Group and Control Group are presented in the table below:

\begin{tabular}{|c|c|c|c|c|}
\hline \multirow{2}{*}{ No } & \multicolumn{2}{|c|}{ Experimental Group } & \multicolumn{2}{c|}{ Control Group } \\
\cline { 2 - 5 } & $\mathbf{X}$ & $\mathbf{X} 2$ & Y & Y2 \\
\hline 1 & 80 & 6400 & 75 & 5625 \\
\hline 2 & 78 & 6084 & 70 & 4900 \\
\hline 3 & 78 & 6084 & 70 & 4900 \\
\hline 4 & 75 & 5625 & 70 & 4900 \\
\hline 5 & 85 & 7225 & 80 & 6400 \\
\hline 6 & 85 & 7225 & 73 & 5329 \\
\hline 7 & 72 & 5184 & 71 & 5041 \\
\hline 8 & 72 & 5184 & 73 & 5329 \\
\hline 9 & 76 & 5776 & 75 & 5625 \\
\hline 10 & 85 & 7225 & 73 & 5329 \\
\hline Total & 786 & 62012 & 730 & 53378 \\
\hline
\end{tabular}

From the data presented, the computation of t-test is in different ways. Calculating the mean score of Experimental Group can be found from the following calculation: 


$$
\mathrm{M}=\frac{\sum x}{N x} \quad \mathrm{M}=\frac{786}{10} \quad \mathrm{M}=78.6
$$

Meanwhile, calculating the mean score of the Control Group can be counted from the following calculation:

$$
\mathrm{M}=\frac{\sum y}{N y} \quad \mathrm{M}=\frac{730}{10} \quad \mathrm{M}=73.0
$$

Calculating the total individual score deviation square of $M_{x}$ $M_{x}$ is as follow:

$$
\begin{aligned}
& M_{x}=\sum_{x^{2}}-\frac{\left(\sum x\right)^{2}}{N_{y}} \\
& M_{x}=62012-\frac{\left(\sum 786\right)^{2}}{10} \\
& M_{x}=62012-\frac{617796}{10} \\
& M_{x}=62012-61779.6 \\
& M_{x}=232.4
\end{aligned}
$$

On the other hand, calculating the total individual score deviation square of $M_{y} M_{y}$ is as follow:

$$
\begin{aligned}
& M_{y}=\sum_{x^{2}}-\frac{\left(\sum x\right)^{2}}{N_{y}} \\
& M_{y}=53378-\frac{\left(\sum 730\right)^{2}}{10} \\
& M_{y}=53378-\frac{532900}{10} \\
& M_{y}=53378-53290 \\
& M_{y}=88
\end{aligned}
$$


Therefore, the calculation of the t-test of students' comprehension of the :

$$
\begin{aligned}
& \mathrm{t}-\text { test }=\frac{M_{x}-M_{y}}{\sqrt{\left(\frac{\left(\sum x^{2}+\sum y^{2}\right)}{N x+N y-2}\right)\left(\frac{1}{N x}+\frac{1}{N y}\right)}} \\
& =\frac{232.4-88}{\sqrt{\left(\frac{(62012+53378}{10+10-2}\right)\left(\frac{1}{10}+\frac{1}{10}\right)}}
\end{aligned}
$$

144.4

$$
=\frac{\sqrt{\left(\frac{115390}{18}\right)(0.2)}}{\sqrt{18}}
$$

$$
=\frac{144.4}{\sqrt{6410.56(0.2)}}
$$

$$
\begin{aligned}
& =\frac{144.4}{\sqrt{1282.11}} \\
& =\frac{144.4}{35.807}
\end{aligned}
$$

$=4.033$

Based on results above, the calculating the degree of freedom :

$\mathrm{Df}=(\mathrm{Nx}+\mathrm{Ny}-2)=(10+10+-2)=18$. The t-test of the significance level of $5 \%$ with Df 18 was 1.734 .

\section{Discussion}

\section{Observation}

The observation reveals that preparing adaptive Pecha Kucha needs longer time than that common Power Point presentation. The adaptive Pecha Kucha is also considered more difficult as they have to memorize and master the material well although they may use note card during the presentation. They must prepare to explain 
clearly and briefly along with the time set in each slide. In addition, selecting pictures appropriate for the materials is not an easy job. With such preparation and its consideration as a new thing for the presenters, no wonder if they admit the technique as a difficult one.

This is different from the common Power Point Presentation that the presenters have been familiar with before. They can prepare and perform the presentation easier than the adaptive Pecha Kucha. However, performing adaptive Pecha Kucha is challenging since the presenters have to explain with the help of pictures. It also invites creativity and most of the presenters are satisfied as it provides them a new way of presenting and explaining. This technique seems to give more benefit than the common Power Point that ask the presenters only to read the slides.

The features of adaptive Pecha Kucha performance are considered to be more interesting by the audience. Its pictures, short duration, and content attract more attention. It invites audiences to focus on what is delivered as they have no other things to pay than presenters and slides. Its length, 20 second, and illustration may avoid boredome as shown by students active involvement and participation toward presenters during the presentation. On the other side, the presenters that tend to prepare a full of words slide make the audience pay their attention to the presentation less as they can read the slides and leave the presenters. With more focus in adaptive Pecha Kucha presentation, students have more understanding to the materials compared to common Power Point presentation.

\section{Questionnaire}

Pecha Kucha technique is considered as a new thing for students even the adaptive one. As an introduction, adaptive technique is choosen so that students are ready to use it gradually. As a new technique, students needs more time to prepare it in terms of the slide preparation and presentation delivery. That is why, the questionnaire results reveal that many students who become presenters admit the technique as a difficult one and need longer time to prepare. All of them take more than two hours to prepare the presentation. 
Every material has its own difficulty level. Either the presentation is aimed to explain or it is aimed to tell, students will need different preparation duration. In addition, choosing the appropriate picture or illustration matched and represented with the sequence of story or presentation flow takes time and not an easy job. The presenters will also have further duty in preparing the presentation in which they have to present comprehensive explanation represented by picture or illustration in a time limit setting. This provides another presure for the presenters to better give their presentation. As a consequence, they need more adequate preparation and practice. However, it is not surprising that the questionnaire reveals that the technique can provide adequate practice for explaining. Almost all speakers admit the benefit of this technique for their explaining skill. This is what is aimed mainly from the use of the technique.

This is in contrast with the common Power Point presentation where the presenters are helped with the explanation on the slide even they cannot explain well. They can hide their low explanation capability behind this condition. They do not need to specifically put picture or illustration in their presentation slide. Putting them is considered optional. They may put it if they want to make their presentation more attractive and better and gain audiences' attention.

A good performance of both techniques is influenced by several factors such as students preferences and their speaking proficiency mastery. Since students has no experience about using the technique before, they are also influenced by a psychological factors such as nervousness, presure, and belief toward the performance. They need to manage those factors well to successfully give the presentation.

Successful presentation must be directed to identify the students response and comprehension. The two aspects are closely related and become important aspects to guarantee that the presentation is purposeful and on target. It cannot be denied that students' attention and focus can drive to comprehension. That is why the adaptive Pecha Kucha can result higher understanding than the common Power Point Presentation as stated in the questionnaire results. This may be debatable since the common Power Point pre- 
sentation may also provide understanding for students. But it is important to note here that the audience may get their comprehension from the text on the slide rather than from the explanation of the presenters. However, it is necessary to underline that with its needs for proper preparation, students focus, and illustrations shows that the application of adaptive Pecha Kucha contributes to the develop students' skill, especially speaking skill.

\section{Comprehension of the Test}

The data analysis showed that the t-statistics is 6.44 , while the value of t-table with the significance level of $5 \%$ and the Df (Degree of Freedom) 18 is 1. 734. It could be said that the t-statistics is higher than t-table. It also prove that the hypothesis which say "there is significant different of exploring adaptive Pecha Kucha technique than for students' presentation skill" is accepted. It shows that the adaptive Pecha Kucha is really effective to do the presentation especially in developing explaining skill. Though, the students need more time and preparation, this technique is badly employed due to its effectiveness and to support the pre-service teachers' development.

\section{Conclusions}

The needs for proper preparation, students focus, and illustrations in applying the adaptive Pech Kucha show that the application of adaptive Pecha Kucha contributes to the develop students' explaining skill, performance and comprehension. With a good preparation and clear rule of performance, the technique shows to be more effective than the common Power Point presentation. The data analysis of students comprehension shows that the tstatistics is higher than t-table. It also proved that the hypothesis which say there is significant different of exploring adaptive Pecha Kucha technique than for students' presentation skill is accepted. It showed that Pecha Kucha is really effective to do the presentation. 


\section{REFERENCES}

Arikunto, S. 2000. Manajemen Penelitian. Jakarta: PT Rineka Cipta.

Best, J.W. 1981. Research in Education. 4th ed. New Jersey, USA: Prentice-Hall. Inc.

Beyer, A. et. al. 2012. Comparing Students' Evaluations and Recall for Student Pecha Kucha and PowerPoint Presentations. Journal of Teaching and Learning with Technology. 1/2: 26 - 42.

Burns, A. \& Joyce, H. 1997. Focus on Speaking. Sydney: NCELTR.

Hadi, S. 1993. Statistik Jilid III. Yogyakarta: Andi Offset.

Lehtonen, M. 2011. Communicating Competence through Pecha Kucha Presentations. Journal of Business Communication. 48/4: 464-481.

Maryam, S. 2011. Using Microsoft Power Point in Speaking Class. Encounter: Journal on English Teaching and Learning. 2/1: 107-125.

McDonough, J \& Shaw, C. 2003. Material and Methods in ELT. Oxford: Blackwell Publishing.

McMillan, J. H. 1992. Educational Research. New York: Harper Cillins Publisher.

Nation, I.S.P \& Newton. J. 2009. Teaching ESL/EFL Listening and Speaking. New York: Routledge.

Richards, J. C. 2008. Teaching Listening and Speaking: From Theory to Practice. Cambridge: Cambridge University Press. 
Pecha Kucha : A Way to Develop Presentation Skill

Shumin, K. 2002. Factors to Consider: Developing Adults EFL Students' Speaking Abilities. J.C. Richards and W.A. Renandya (Eds.), Methodology in Language Teaching: An Anthology of Current Practice. New York: Cambridge University Press.

www.pecha-kucha.org. Accessed on April 10, 2014. 
